\title{
Electricity industry restructuring in Australia: underlying principles and experience to date
}

\author{
Hugh Outhred \\ University of New South Wales \\ h.outhred@unsw.edu.au
}

\begin{abstract}
Electricity restructuring is a complex, never-ending process that has engineering, economic, social, commercial, legal and policy dimensions and takes place within a broad societal context. Thus, there are many interdisciplinary challenges for the design, implementation and on-going maintenance of a successful restructuring process. Moreover, it is not possible beforehand to be sure that a particular design will work satisfactorily because the formally designed aspects of a restructured industry are only part of the whole. Therefore, it is most important to approach the design of restructuring in manner that is as robust as possible over both the short and long term. This paper describes the underlying principles used in restructuring the Australian electricity industry and discusses outcomes to date and current challenges.
\end{abstract}

\section{Introduction}

Electricity restructuring is a complex, never-ending process that has engineering, economic, commercial, legal and policy dimensions and takes place within a broad societal context that itself influences and is influenced by the outcome. Thus, there are many interdisciplinary challenges for the design, implementation and ongoing maintenance of a successful restructuring process.

Moreover, a restructuring process can only be partially designed in a formal manner, because important aspects of restructuring reside in the wider societal context. In addition, key questions cannot be formulated as disprovable hypotheses. Thus, it is not possible to be sure beforehand how a particular design will work in practice.

Therefore, it is important to approach the process of restructuring in manner that is robust over both the short and long term. This includes the challenge of building and sustaining a social consensus about:

- The objectives of restructuring, including the assignment of tasks to centralized and decentralized decision making
- The restructuring transition path, which has proved to be a multi-decade process

- Procedures to develop, implement and continue to evolve formal rules that are compatible with, and place obligations on, the surrounding formal societal context as it evolves.

\section{The social context for electricity industry restructuring}

Hardin [1] argues that there is a class of human problems that have no technical solution and thus are interdisciplinary, in the sense that they require the individual contributing disciplines to merge their thinking to find a solution. Electricity industry restructuring is a problem of that kind.

One reason for this is that electricity industry restructuring implies changing the balance between resources that are shared by a group (eg the resources of a monopoly electricity utility are shared between the utility's customers) and resources that are individually assigned and controlled. Hardin uses the concept of the tragedy of the commons to explore this question and comes to the conclusion that we must seek answers to problems of this kind in the form of "mutual coercion, mutually agreed upon", in which a group of people agrees to place constraints on their individual behavior for the good of the group. This, I would argue, could be used as a model for electricity industry restructuring. Note, however, that in that context, it implies the following restructured industry framework:

- A set of rules with which all electricity industry participants agree to abide in making decisions (including all stages in the energy conversion chain from primary resources to end-use energy services) - with coercion if they do not. These rules are normally designed to maximize economic efficiency. However, there are differing views on which rules achieve economic efficiency - eg the debate between energy-only and energy plus capacity markets.

- The placing of a set of constraints on decisionmakers external to the industry who can 
influence industry outcomes (eg policy makers, regulators and the general public).

- Consistency in the overall decision-making framework over the decadal timescale that is relevant to electricity industry decision-making.

The design of industry-specific rules for the electricity industry can be informed and guided by an understanding of its specific characteristics, which intrinsically place constraints on participant decisionmaking. These may be regarded as mutual coercion based on objective engineering requirements, for example to maintain power system security. These objective engineering requirements have (at least until recently) applied more strongly in the large generation and transmission sectors of the industry than for distribution, distributed generation and end-use.

However, increasing social dependence on the electricity industry, for example for space cooling, along with static or declining supply quality and reliability, rising network costs, network easement constraints, innovation in distributed energy resource technology and growing concern about environmental impacts, are extending the need for objective requirements into the distribution and end-use sectors.

Further relevant issues are explored in [2, $3 \& 4]$.

\section{Development of the formal electricity industry model used in Australia}

The formal model that has been adopted for electricity industry restructuring in the Australian National Electricity Market evolved from research that commenced in the late 1970s. That early work introduced the concept of spot pricing and the need for strong compatibility between the market model of an electricity industry and its underlying physical operation [5, 6]. Following that, [7] considered the implications of inter-temporal links and uncertainty for pricing theory and recommended the use of a spot and derivative pricing structure to support investment instead of the traditional capacity payment approach. [8] explored the question of how industrial consumers could operate in a spot and derivative market and [9] considered spot and forward market operation in the broader electricity industry context. Overall, this conceptual work considered the full energy conversion chain from primary to end-use energy forms.

The restructured industry model that is now implemented in the Australian National Electricity Market (NEM) was first proposed in [10] and [11] and is described more fully in [12]. Ref. [13] describes the practical compromises required in representing network services in an electricity spot and derivative market of the NEM type, while [14] reports on experimental testing of the then proposed NEM design for wholesale spot energy and short-term derivative markets prior to their implementation.

Implementation of the NEM to date has focused on the large generation and transmission sectors, with electricity retailers used as a surrogate for direct enduser participation. References [15, $16 \&$ 17] discuss potential refinements to the NEM model that would give closer compatibility between the market models and engineering reality, with respect to integrating management of availability and quality of supply, enduser participation and stochastic renewable energy resources into the NEM framework.

This body of work provided a strong understanding of the underlying principles and practical challenges of electricity industry restructuring prior to its actual implementation in Australia. This understanding was, and continues to be, transferred to industry and policy makers by an on-going series of short courses that commenced in 1989 and continues to evolve.

One of the ironies of electricity industry restructuring is that the complexity of restructuring is greater for the distribution and end-use sectors of the industry than for the large generation and transmission sectors. Also, significant innovation in technology and behavior is required and the transition path is less clear. Moreover, the objective constraints that can be used to justify rules for "mutual coercion, mutually agreed up" are less obvious and less influential in the distribution and end-use sectors. Thus it is not surprising that Australian electricity industry restructured has not progressed as far or as fast in distribution and end-use as in generation and transmission. Further progress is now being facilitated through technical progress such as interval metering.

\section{Features of the formal electricity industry model used in Australia}

An electricity industry implements an energy conversion chain from primary energy resources to end-use energy forms, for the purpose of delivering desired end-use energy services. The industry-specific value is created by the values that end-users attach to the delivery of the end-use energy services, while the industry-specific costs derive from the investment and operating costs associated with the equipment required to implement the energy conversion chain. Electricity industry equipment can be categorised as follows:

- Primary energy equipment is associated with the extraction and processing of primary energy forms. Such equipment is sometimes regarded as lying outside the electricity industry but is essential to achieving its goals. 
- Electricity generation equipment is associated with conversion of primary energy forms to electrical energy. This is usually described as electricity generation or power station equipment. Electricity generation equipment only provides the capability to create electrical energy. Because electrical energy is not storable in a cost-effective manner, generators can only create a flow of electrical energy if they are connected to end-use equipment via a closed-current path. Moreover, the end-use equipment must be ready to extract a flow of electrical energy from the network for the energy conversion chain to function correctly.

- Network equipment is used to create closedcurrent paths between electricity generation equipment and end-use equipment and to maintain the availability and quality of the energy flowing through the network. It is subdivided into transmission and distribution categories.

- End-use equipment converts electrical energy to end-use energy forms, and in the process delivers the end-use energy services that are the desired outcomes from the electricity industry.

The industry configuration is shown in Figure 1, in which distributed and renewable energy resources are taken into account.

Any mismatch between the flow of primary energy injected into an electricity generator and the flow of electrical energy extracted from that generator by the network and end-use equipment, typically appears as a change in the kinetic energy of the rotating masses associated with the generating equipment. This in turn modifies the frequency of the sinusoidal voltage and current waveforms in the power system. The behaviour of generator, end-use and network equipment also influences the voltage profile in the power system.

Thus, an electricity industry such as that associated with the Australian NEM has important physical attributes that must be continuously managed to ensure effective operation [15]:

- Continuity of electrical energy flow - from generators to end-use equipment - must be maintained to avoid local or widespread blackouts, by a process known as maintaining availability of supply. This is because electrical energy cannot be cost-effectively stored.

- Quality of supply - as measured by voltage magnitude, frequency and waveform purity must be kept within specifications for electrical equipment to function correctly, by a process known as maintaining quality of supply.

System-wide management is required to guard against widespread blackouts or total system collapse, while local management is required to meet the availability and quality design specifications of individual items of generator, network and end-use equipment.

At the system-wide level, the power system operator (eg. NEMMCO in the Australian NEM) aims to keep power system operation within a secure operating envelope with sufficient reserve capacity that "credible" equipment failure will not lead to a blackout or unacceptable quality of supply. Figure 2 illustrates this for a restructured electricity industry that incorporates an electricity market.

As illustrated in Figure 2, a number of tools can be used to manage system-wide power system operation in a restructured electricity industry:

- While the power system is operating within a secure operating envelope, market processes can be used to manage overall supply-demand balance as described below for the NEM.

- A wholesale spot market for market interval energy injected by a generator or extracted by an end-user at a point of connection, using a hybrid 5/30-minute market interval and a market model with an abstract representation of high-level network losses and flow constraints (Figure 3). This market solves a securityconstrained dispatch at 5-minute intervals.

- Spot markets for ancillary service capabilities that are used to manage supply-demand balance within each spot market interval (known as frequency control ancillary services). These also use the same abstract representation of network losses and flow constraints.

- Informal derivative markets associated with the above spot markets, which provide forward price discovery but (as currently implemented) no aggregate forward volume discovery.

- When power system security is seriously threatened, engineering procedures are used to manage major security risks. Market processes are unlikely to work well in these circumstances because the broad public interest is at stake, rapid responses are required, and some participants may be able to exercise market power. However, commercial contracts can still be used to procure the necessary rapid response capabilities.

- The rapid response capabilities must be invoked (usually by pre-set automatic triggers) if power system security has actually been jeopardised. Under these circumstances, the greater public good may override the legitimate interests of individual industry participants through mechanisms such as involuntary load shedding. 
To date, a simpler approach is used to manage availability and quality of supply at the local level compared to the system-wide level. This is partly because of the challenges associated with restructuring the distribution and end-use sectors and partly because sophisticated end-use metering and response strategies have, until recently, been too expensive to implement in a cost-effective manner.

However, recent developments in information and communication technologies, power electronics and small-scale generation and storage are opening up new opportunities for distributed energy resources (DER), which include flexible demand, and generation or reversible storage embedded in a distribution network or located in end-user premises [18].

These developments offer the potential for a major shift in the way electricity industries are designed and operated. DER can play a very important role because of the strong symmetry in the electricity industry:

- The industry's continuous flow nature and lack of intermediate electrical energy storage means that, for small perturbations, a reduction in the rate of electrical energy demand is equivalent to an increase in the rate of electrical energy supply at the same network location.

- The fungible nature of electrical energy (it can be created from and converted into many different energy forms) means that, if the flow of electrical energy through a network is constrained for some reason, a reduction in demand by one end-use downstream of the network flow constraint can allow an increase in demand by another end-use that is also downstream of the network flow constraint.

Thus DER can contribute to maintaining local availability of supply by voluntarily and rapidly reducing the flow of electrical energy:

- at any location in the network in response to a temporary shortage of generating capacity; or

- at a point of connection downstream of a network flow constraint.

DER can also contribute to maintaining local quality of supply by:

- $\quad$ acting continuously to maintain local voltage or local waveform purity within specification; or

- $\quad$ responding only when needed to restore local voltage or local waveform purity to within a specified tolerance band.

DER can also contribute to managing system-wide availability and quality of supply. For example, NEMMCO already takes advantage of the inherent voltage and frequency response of end-use equipment in managing power system security. However, this contribution is not recognised in the NEM ancillary service commercial arrangements and so is not commercially rewarded. Similarly, to date the NEM structure does not provide a "level playing field" for wind energy or other non-storable, stochastic renewable energy resources [17].

More generally, the NEM structure provides a poor interface for end-users, distributed and renewable energy resources and is thus biased towards the large generation sector. This is partly due to the priorities by which electricity industry restructuring has been implemented to date [19]. This should not be surprising because the adequacy of a set of rules (eg the National Electricity Rules) is commonly assessed in the existing context rather than with respect to possible futures that may arise.

In summary, key elements of the formal implementation of electricity industry restructuring in Australia are:

- A multi-state "National" Electricity Market (NEM) that is consistent in most aspects across state borders and that implements a hub-andspoke approximation to nodal pricing.

- Disaggregation of generation, network and retail services

- A single NEM market \& system operator

- Formal spot energy and FACS markets (security constrained dispatch) designed for supply/demand symmetry

- Informal derivative markets

- Security assessment to 10 year horizon

- An as yet incomplete process of integrating end-users and distributed and renewable energy resources.

\section{Features of the restructuring process}

The Special Premiers' Conference in July 1991 agreed to "establish a National Grid Management Council [NGMC] to encourage and coordinate the most efficient, economic and environmentally sound development of the electricity industry in eastern and southern Australia having regard for key national and State policy objectives" [20]. This established an early consensus between most Australian governments (with the exception of Western Australia) on the objectives for electricity industry restructuring. However, the distribution and end-use sectors were largely quarantined from the restructuring process except for the vaguely defined concept of "full retail competition"

One practical outcome of this consensus occurred in February 1994, when the Council Australian Governments (COAG) agreed to develop a Code of Conduct for the operation of the National Grid [19, Clause 1.2.1], where the National Grid was defined as "the sum of all connected transmission systems and distribution systems within the participating 
jurisdictions" [21, Glossary], which were Queensland, New South Wales, South Australia and the Australian Capital Territory. The National Grid is a power system that extends over $4000 \mathrm{~km}$. Tasmania physically joined the National Grid in 2005 when commissioning tests began on the DC cable joining it to the mainland.

In 1996, the participating jurisdictions agreed to pass the National Electricity Law, "being the schedule (as amended from time to time) to an act of the parliament of South Australia entitled National Electricity (South Australia) Act 1996" [21, Glossary]. This provides the legal basis for the restructured industry, including the National Electricity Code and the key institutions, such as the National Electricity Market Management Company (NEMMCO), which operates the National Electricity Market. The other participating states agreed to abide by this Act, creating a largely consistent legal basis for the interconnected power system. It has since been amended.

The NGMC released the National Electricity Market (NEM) Code of Conduct (version 1.0) in February 1996. This later evolved into the National Electricity Code (NEC) and has recently been given clearer legal status as the National Electricity Rules.

These outcomes provide clear evidence of a consistent consensus approach to restructuring between the jurisdictions involved. However, that consensus did not extend to questions of ownership or to treatment of distribution, DER and end-users.

Prior to restructuring, each jurisdiction owned (in large part) the electricity supply industry within its borders. As a result, each jurisdiction determined the extent of disaggregation and privatisation of its industry. Victoria has proceeded furthest in both disaggregation and privatisation; South Australia has leased its supply industry assets on long-term leases while the electricity supply industries in New South Wales and Queensland remain in government ownership.

Each jurisdiction also decided the pace and extent of restructuring for distribution and end-users. For example, Queensland has only recently agreed to implement retail competition for residential and small commercial end-users.

The outcomes of restructuring have been controversial in various ways, particularly the privatisation processes in Victoria and South Australia. Also, the final report of the 2002 COAG energy market review concluded that "NSW needs more competing generators, and more dispersed generator ownership" [22, page 21]. It recommended, "the New South Wales government should further disaggregate its generation assets" [22, page 50].
Following the COAG energy market review, a second phase of restructuring has commenced, with a focus on the following issues:

- Implementing the COAG national energy policy framework through the Ministerial Council on Energy (MCE), with work programs in energy efficiency, energy market reform (including en-user participation), energy security, renewable energy and distributed generation.

- Improving governance and institutional arrangements, including the creation of an Australian Energy Regulator and an Australian Energy Market Commission

- Improving economic regulation of energy network service providers, including provisions governing network augmentation

- Promotion of greater engagement of end-users through full retail competition, interval metering and demand response.

\section{Strengths and weaknesses of the current arrangements}

The Australian NEM has a number of important strengths $[15,19]$ :

- World-leading designs for wholesale spot energy and frequency control ancillary service markets.

- World-leading procedures to project and manage power system security.

It also has important weaknesses [15-19, 23]:

- At present the retail markets associated with the NEM are dysfunctional in their design and, in particular, provide a poor interface for distributed and renewable energy resources. The retail markets retain, to a large degree, the traditional philosophy of an open-ended obligation to serve and predetermined costrecovery tariffs. To date, "full retail competition" has not produced genuine competition between supply and demand side options.

- The large geographical scope of the NEM coupled with low population density creates challenges in maintaining power system security and increases the likelihood of network flow constraints. These must be dealt with carefully in implementing the securityconstrained dispatch in the NEM spot market, and this issue would benefit from further refinement.

- The large geographical scope of the NEM also creates challenges in delivering efficient 
network augmentation investment. The present approach to network service regulation has largely retained the traditional cost-recovery approach and creates biases between existing and new-entrant generation in terms of network charges, and against DER options as alternatives to network augmentation.

- Voltage-related quality of supply is managed by a regulated, engineering-oriented approach that fails to adequately value potential DER contributions.

- The industry has excessive climate change emissions resulting from its reliance on coalfired power stations but there are few effective incentives for new low emission generation such as wind energy. Climate change policy needs urgent attention [24].

The weaknesses outlined above could be overcome by incremental enhancements to the present implementation of electricity industry restructuring. These include the following:

- Introduce formally designed derivative markets for CfDs and call options to promote end-user participation and facilitate commercial risk management of spot market risk (the initial code released in 1994 included a formal short term forward market).

- Include more accurate models of network services in spot \& formal derivative markets for energy and ancillary services, so that derivative markets contain information on potential future flow constraints.

- Introduce a more market-oriented approach to managing power system security and availability \& quality of supply, so that distributed resource providers (including wind farms) can be rewarded (penalised) for improving (worsening) availability and quality of supply.

- Adopt a revenue cap approach to regulating distribution network service providers (DNSPs) and engage them in promoting distributed resource development.

- Allow distribution network service providers (DNSPs) to install (and recover the costs of) interval meters for small end-users that measure energy and key availability and quality parameters, and develop associated communication and control protocols and database structures to allow small end-users to express value for, and contribute to managing, local and system-wide availability and quality.

- Introduce direct network access contracts between DNSPs and end-users (and embedded generators) that clearly spell out mutual obligations with respect to availability and quality of supply and that efficiently allocate constrained network flows by spot and derivative network access tariffs authorised by the Australian Energy Regulator (AER).

- Refine commercial arrangements for Network Control Ancillary Services.

- Merge retail and wholesale markets into a consistent set of spot $\&$ derivative markets for energy, network access and ancillary services, and migrate electricity retailers towards an energy service company (ESCO) role [26].

- As a longer-term goal, further develop this integrated wholesale and retail market structure to incorporate market-based voltage quality management [15].

The integration of formally designed wholesale and retail markets with would lead to the industry structure shown in Figure 4.

\section{Lessons learned \& future prospects}

Electricity industry restructuring is a complex and continuing process that itself occurs within an evolving social framework. Success depends on establishing and maintaining a consensus on the key objectives and principles. The following appear to have been important to the relative stability and success of the Australian restructuring process to date:

- Early development of a formal model for a restructured electricity industry that achieved compatibility between the economic model and the underlying physics of electricity industry restructuring, that supported a robust transition path and that supported continued evolution to a more refined practical realization. This provided an objective basis for "mutual coercion, mutually agreed upon".

- Restructuring process arrangements that achieved a separation of powers between the development and authorization of the necessary protocols and that supported peer review, effective public participation, and consensus building.

- An education program that supported informed participation by industry stakeholders.

However, the dynamic and evolving nature of the broader social context means that there can be no guarantee of future stability and continuity in approach to electricity industry restructuring. For example [25] opens up the possibility of a complete re-think of the current approach to addressing the perennial and irresolvable (in a deterministic sense) question of "resource adequacy". 


\section{References}

[1] G Hardin, "The Tragedy of the Commons", Science, Vol 162, December 1968, pp 1243-1248.

[2] J Ravetz, "Global Systems Failures", A report for the James Martin Institute, Said Business School, Oxford University, May 2005. Available: www.jerryravetz.co.uk.

[3] L Gunderson, C S Holling, L Pritchard, and G D Peterson, "Resilience", Volume 2, The Earth system: biological and ecological dimensions of global environmental change, pp 530-531 in Encyclopedia of Global Environmental Change (ISBN 0-471-97796-9).

[4] S R Thorncraft, H R Outhred and D J Clements, "Heuristics to Assist in Understanding the Complexity of a Restructured Electricity Industry", IEEE Power Engineering Society Annual Meeting, June 18-22, 2006.

[5] F C Schweppe, J L Kirtley, R D Tabors, H R Outhred, F H Pickel and A J Cox, "Homeostatic Utility Control", IEEE Transactions on Power Apparatus and Systems, Volume 99, 1980, pp 1151-1163.

[6] H R Outhred and F C Schweppe, "Quality of Supply Pricing", Proceedings of the Institute of Electrical and Electronic Engineers (IEEE) Power Engineering Society Winter Power Meeting, 1980, Paper A 80 084-4.

[7] R J Kaye and H R Outhred, "A Theory of Electricity Tariff Design for Optimal Operation and Investment", IEEE Trans. on Power Systems, Vol. 4, No. 2, May 1989, pp 606 613.

[8] H R Outhred, C H Bannister, R J Kaye, Y B Lee, D Sutanto, M Manimaran, "Electricity Pricing for Optimal Operation and Investment by Industrial Consumers", Energy Policy, Special Issue on Spot Pricing, Vol. 16, No. 4, August 1988, pp 384-393.

[9] R J Kaye, H R Outhred and C H Bannister, "Forward Contracts for the Operation of an Electricity Industry under Spot Pricing", Paper 89 SM 828-5 PWRS, IEEE Transactions on Power Systems, Vol. PWRS-5, No. 1, Feb. 1990, pp 46-52.

[10] H R Outhred and R J Kaye, "Choices for the Future of Australia's Electricity Industries", Proceedings of the International Mechanical Engineering Congress, Conference 4: Energy, IEAust., Sydney, July 1991, pp 29-33.

[11] H R Outhred, R J Kaye and C H Bannister, "Beyond the National Grid Draft Protocol", Proceedings of the Electric Energy Conference, Brisbane, 19-21 October, 1992.

[12] H R Outhred, "Principles of a Market-Based Electricity Industry and Possible Steps Toward Implementation in Australia", Proceedings of the International Conference on Advances in Power System Control, Operation and Management, Hong Kong, 7-10 December 1993.

[13] H R Outhred and R J Kaye, "Incorporating Network Effects in a Competitive Electricity Industry: An Australian Perspective", Chapter 9 in M Einhorn and R Siddiqi (eds),
Electricity Transmission Pricing and Technology, Kluwer Academic Publishers, 1996, ISBN 0-7923-9643-X, pp 207228.

[14] H R Outhred and R J Kaye, "Structured Testing of the National Electricity Market Design: Final Report", A Report for the National Grid Management Council, Unisearch, September 1996

[15] H R Outhred, "Managing Availability, Quality and Security in a Restructured Electricity Industry with Reference to the Australian National Electricity Market", Proceedings of the 39th Hawaii International Conference on Systems Sciences, Maui, 3-6 January 2006, ISBN 0-76952507-5.

[16] H R Outhred, and I MacGill, "Electricity Industry Restructuring for Efficiency and Sustainability - Lessons from the Australian Experience", 2006 ACEEE Summer Study on Energy Efficiency in Buildings, Asilomar, August 2006.

[17] H R Outhred and I MacGill, "Integrating Wind Energy in the Australian National Electricity Market", World Renewable Energy Congress IX, Florence, August 2006.

[18] D Crossley A Baitch and H Outhred, Options for Demand Side Response in the National Electricity Market, Initial Overview Report, prepared for the Ministerial Council on Energy Demand Side Response Working Group, 2006.

[19] H R Outhred, "The Evolving Australian National Electricity Market: An Assessment" in Power Progress: An Audit of Australia's Electricity Reform Experiment edited by Graeme Hodge, Valarie Sands, David Hayward and David Scott, Australian Scholarly Publishing, Melbourne, ISBN 1 74097034 9, 2004.

[20] National Grid Management Council, National Grid Protocol First Issue, December, 1992.

[21] National Electricity Code Administrator, National Electricity Code Version 1 (as amended 1998-2003).

[22] Parer W, Agostini D, Breslin P and Sims R, "Towards a Truly National and Efficient Energy Market", Energy Market Review Final Report, Council of Australian Governments, 2002.

[23] Thomas R, Whitehead J, Outhred $\mathrm{H}$ and Mount T, "Transmission System Planning - The Old World Meets the New”, IEEE Proceedings, ISSN 0018-9219, Vol 93, No. 11, November 2005, pp 2026-2035.

[24] DuPont A and Pearman G (2006), Heating up the Planet - Climate Change and Security, Lowy Institute Paper 12. Available: www.lowyinstitute.org.

[25] AEMC Reliability Panel, Comprehensive Reliability Review, Australian Energy Market Commission, May 2006. Available: www.aemc.gov.au.

[26] H R Outhred and I F MacGill, "Electricity Industry Restructuring for Efficiency and Sustainability: Lessons from the Australian Experience", 2006 ACEEE Summer Study on Energy Efficiency in Buildings, pp 8.229-8.240. 


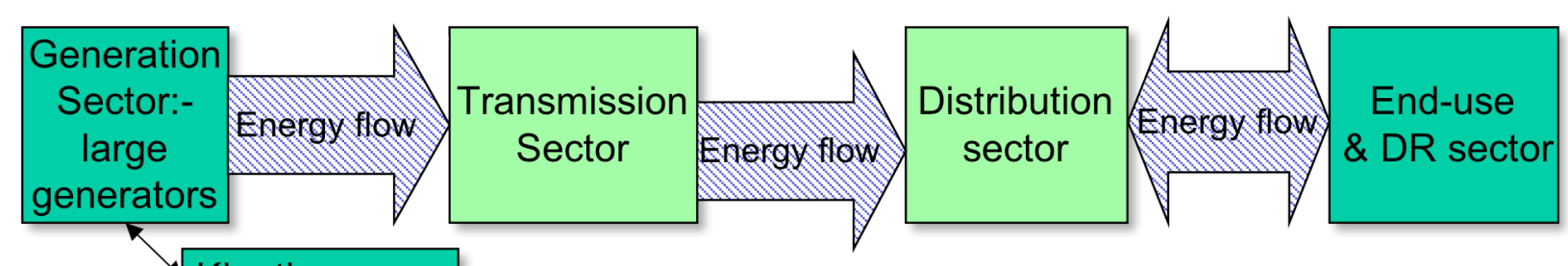

Kinetic energy

Figure 1. The electricity industry energy conversion chain taking account of distributed resources

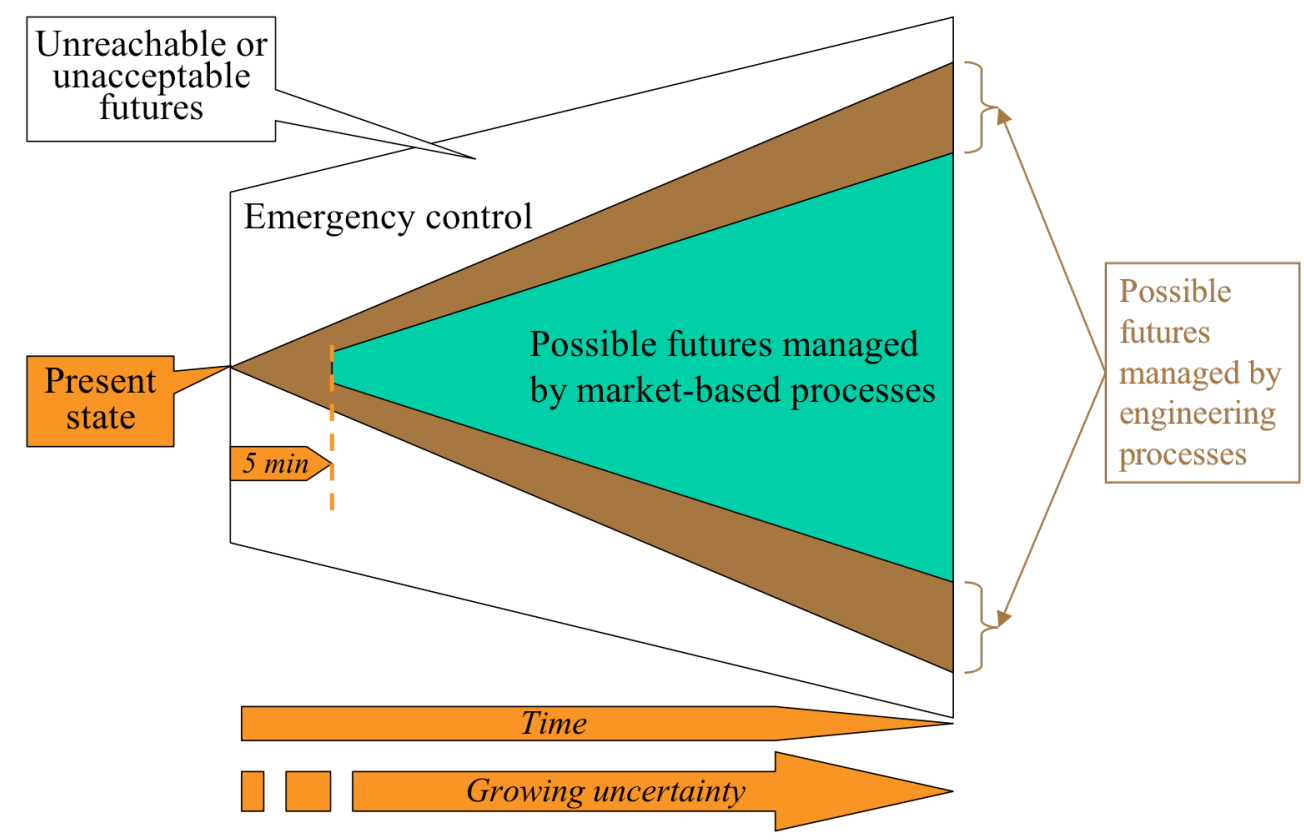

Figure 2. Engineering and Market Processes for Managing Availability and Quality of Supply in a Restructured Electricity Industry 


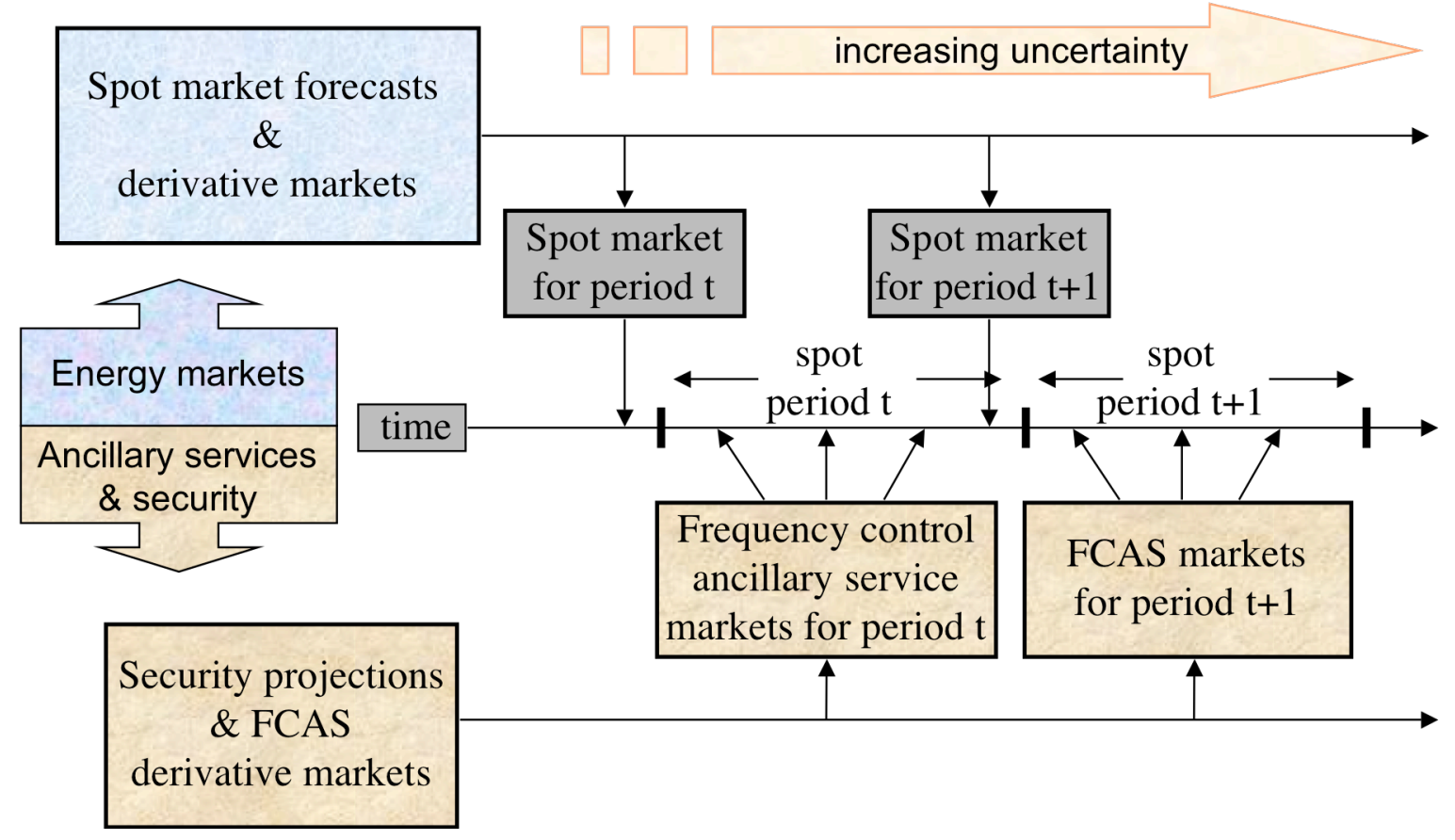

Figure 3. Wholesale market structure and security management in the NEM

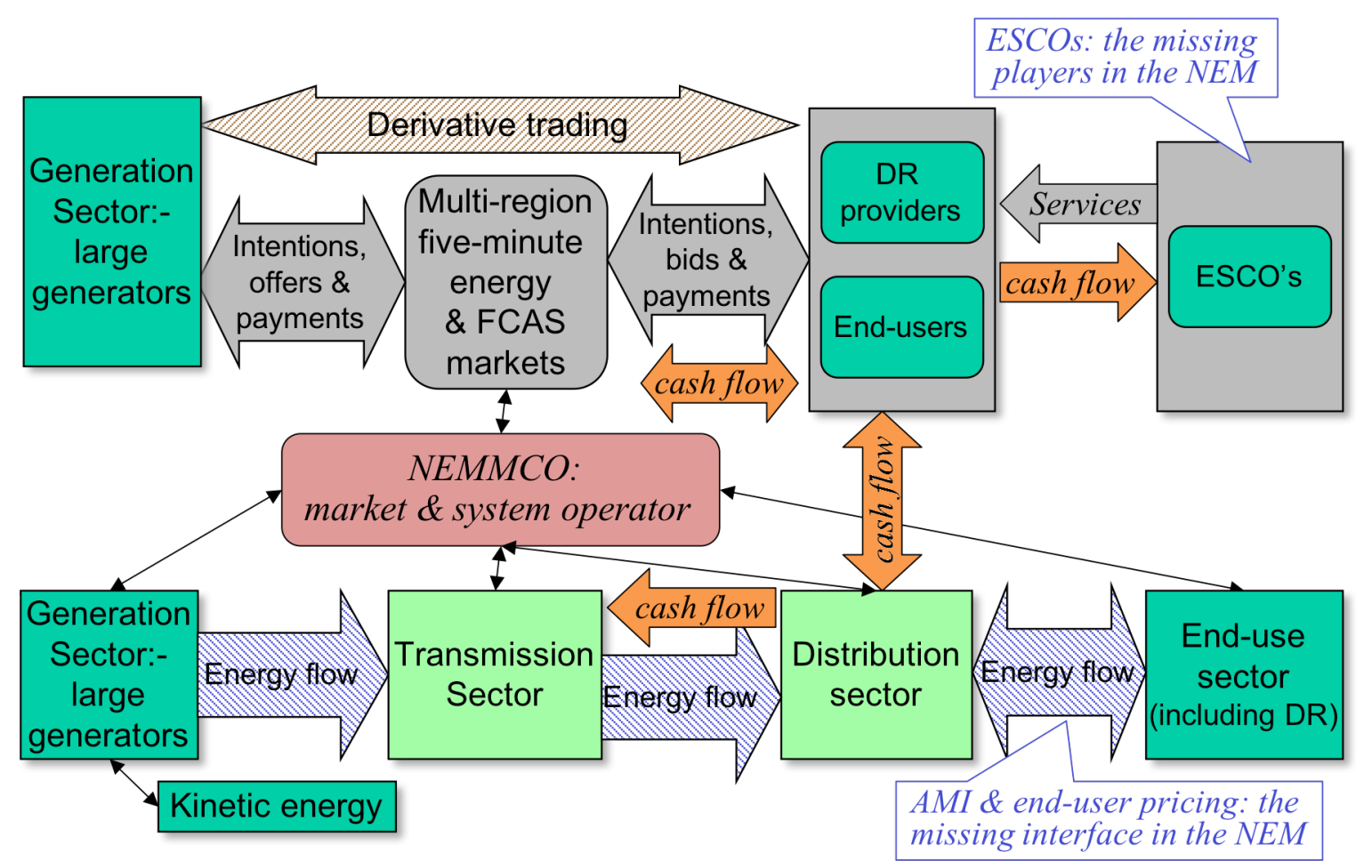

Figure 4. Enhanced NEM with integrated wholesale and retail markets, advanced Metering interface (AMI) and Energy Service Companies (ESCOs) 